\title{
O Globo e a Produção de Memórias sobre o Sistema Único de Saúde (SUS)
}

Izamara Bastos MACHADO ${ }^{1}$

Resumo:

Este trabalho propõe uma discussão sobre a história e a memória do Sistema Único de Saúde, o SUS, construídas a partir das narrativas jornalísticas do jornal $O$ Globo no ano de 1988. Pretende-se discutir a relação entre história, memória e jornalismo e as contribuições do jornalismo, especialmente da grande imprensa comercial, na construção de sentidos sobre a saúde pública.

Palavras-chave: Jornalismo. Memória. Imprensa. Sistema Único de Saúde (SUS). Saúde pública.

\section{$O$ Globo and the production of memories about the Unified Health System (SUS)}

\begin{abstract}
:
In this article, we discuss the history and memory of the Unified Health System (Sistema Único de Saúde - SUS) from the perspective of the journalistic narratives found in $O$ Globo newspapers in the year of 1988 . We aim at correlating history, memory and journalism, as well as investigating how journalism - especially from the big commercial press - in the construction of meanings about public health.
\end{abstract}

Keywords: Journalism. Memory. Press. Sistema Único de Saúde (SUS). Public health.

\section{O Globo y la producción de memorias sobre el Sistema Único de Salud (SUS)}

\begin{abstract}
:
Este trabajo propone una discusión sobre la historia y la memoria del Sistema Único de Salud, el SUS, construidas a partir de las narrativas periodísticas de lo periódico $O$ Globo en el año 1988. Se pretende discutir la relación entre historia, memoria y periodismo y las contribuciones del periodismo, especialmente de la gran prensa comercial, en la construcción de significados sobre salud pública.
\end{abstract}

Palabras clave: Periodismo. Memoria. Prensa. Sistema Único de Saúde (SUS). Salud pública.

\footnotetext{
${ }^{1}$ Doutora e mestre em Comunicação e Cultura pela Escola de Comunicação (ECO) da UFRJ. Jornalista. Pesquisadora do Laboratório de Pesquisa em Comunicação e Saúde (LACES) do Instituto de Comunicação e Informação Científica e Tecnológica em Saúde (ICICT) da Fundação Oswaldo Cruz (FIOCRUZ). Integrante dos Grupos de Pesquisas: 1) Núcleo de Estudos em Comunicação, História e Saúde - Nechs (Laces/Icict/Fiocruz); 2) Mídia, Memória e Temporalidades - Memento (Nepcom/ECO/UFRJ); 3) Comunicação e Saúde, (Laces/ICICT/Fiocruz). E-mail: bastos.iza@gmail.com.
} 


\section{Introdução}

A quem compete a construção da memória de uma pessoa ou de uma sociedade? Quem constrói a história? Poderíamos considerar a mídia como um lugar de memória? A quem cabe contar e recontar decisões políticas que impactem uma nação? Os documentos oficiais governamentais? Os próprios atores envolvidos? Os livros de história? Qual o papel da imprensa na produção de memória(s)? Alguns autores propõem, há tempos, debates importantes que discorrem sobre questões que envolvem temas como história, memória e comunicação.

Halbwachs, em sua obra fundadora A memória coletiva (2006), apresentou a memória como uma reconstrução do passado que se faz sempre a partir do presente, além de propor uma oposição entre história e memória. Nora (1993) debate sobre os lugares da memória, afirma que são instrumentos de poder e que existe certa obsessão pela memória, que é transformada em arquivo. No que diz respeito à história e à memória, Ricoeur (2007) discute os diferentes modos de retratar o passado, entre eles a ficção narrativa, o conhecimento histórico e as operações da memória, propondo distinções importantes entre os termos. Pollak, nas obras Memória, esquecimento, silêncio (1989) e Memória e identidade social (1992), também propõe discussões essenciais sobre questões que envolvem a construção da memória.

Mas, e a imprensa? Como tratar desses debates quando usamos os meios de comunicação como fonte e também objeto de investigação? Tais inquietações nos levaram a autores nacionais e estrangeiros, como Ribeiro (1995, 2014); Huyssen (2000); França (2004, 2012); Chartier (2013); Dosse (2013); Barbosa (2007, 2016), dentre outros. Pesquisas que apresentam a relação Comunicação e História podem ser encontradas na academia há algum tempo. Barbosa e Ribeiro (2011, p.10) já destacaram:

\footnotetext{
Ainda que haja uma espécie de partilha temporal entre esses dois lugares de produção de saber reflexivo, cabendo à história desvendar a possibilidade de ações envolvendo vidas passadas, e à comunicação refletir, prioritariamente, sobre processos envolvidos nas ações dos homens do presente, há outras especificidades que determinam o lugar de fala de cada um desses campos.
}

Propomos, aqui, inserir questões da saúde pública brasileira nos debates que envolvem mídia, história e memória. Consideramos que o jornalismo ocupa um lugar privilegiado nas discussões sobre saúde e contribui para a construção de memórias da área. Mais do que fazer história ou armazenar memórias, os jornais também contam histórias. Histórias que são enquadradas, fragmentadas, editadas e produzidas. Consequentemente, essas histórias 
contribuem para as diferentes memórias que são construídas ao longo do tempo.

Dito isso, questionamos: como foram narradas as notícias sobre a criação do Sistema Único de Saúde (SUS)? De que maneira a imprensa revelou ao público a criação de uma política de saúde pública que se pretendia universal e gratuita em território brasileiro? Que tipo de narrativa os jornais utilizaram para contar à população que uma grande mudança no setor de saúde brasileiro estava se iniciando na década de 1980 ?

O tempo presente nos convida a revisitar o passado frequentemente, inclusive para nossas projeções no futuro. Nos últimos meses, o Brasil e o mundo enfrentam uma histórica pandemia. O Sars-Cov-2, vírus responsável pela Covid-19, fez com que vários sistemas de saúde, de diferentes países do mundo, ganhassem destaque na mídia. No Brasil, com o SUS, não foi diferente. Desde fevereiro de 2020, quando o primeiro caso foi confirmado no país, não faltaram publicações na mídia que abordassem o sistema de saúde brasileiro e a Covid19: "Coronavírus ainda não atingiu o Brasil do SUS"; "O SUS tem reagido bem ao coronavírus, mas é preciso investir mais em leitos; “" “Avanço do coronavírus expõe urgência de valorização do SUS"; "SUS corre risco de colapso"; "Pandemia do coronavírus é a maior prova de fogo do SUS"; "Escassez no SUS: profissionais da saúde relatam batalha contra coronavirus"; "Os impactos da Covid-19 na transformação do sistema de saúde"; "Covid leva classes média e alta de SP a valorizar o SUS, diz pesquisa"; 9 entre dezenas de outras publicações. Desde a chegada do novo vírus ao país, a imprensa não apenas tem se dedicado a fazer coberturas sobre a Covid-19 e suas consequências, em múltiplas abordagens, mas também tem colocado o SUS em pauta.

Conforme já visto em outros estudos (MACHADO, 2014, 2020; LANGBECKER; CASTELLANOS; CATALAN-MATAMORO, 2020), há décadas nos deparamos com narrativas midiáticas sobre o sistema público de saúde, que ao longo do tempo sofreu ataques

\footnotetext{
${ }^{2}$ O Globo, 06/03/2020. Disponível em: https://oglobo.globo.com/analitico/coronavirus-ainda-nao-atingiu-brasildo-sus-24290058.

3 UOL, 11/03/2020. Disponível em: https://www.redebrasilatual.com.br/saude-e-ciencia/2020/03/avanco-docoronavirus-expoe-urgencia-de-valorizacao-do-sus/.

4 Rede Brasil Atual, 19/03/2020. Disponível em: https://www.redebrasilatual.com.br/saude-eciencia/2020/03/avanco-do-coronavirus-expoe-urgencia-de-valorizacao-do-sus/.

${ }^{5}$ Isto é, 20/03/2020. Disponível em: https://istoe.com.br/sus-corre-risco-de-colapso/.

6 JC, 22/03/2020. Disponível em: https://jc.ne10.uol.com.br/pernambuco/2020/03/5603069-pandemia-docoronavirus-e-maior-prova-de-fogo-do-sus.html.

${ }^{7}$ Exame, 28/03/2020. Disponível em: https://exame.com/brasil/escassez-no-sus-profissionais-da-saude-relatambatalha-contra-coronavirus/.

${ }^{8}$ Veja-Saúde, 23/04/2020. Disponível em: https://saude.abril.com.br/blog/com-a-palavra/os-impactos-da-covid19-na-transformacao-do-sistema-de-saude/.

9 Agência Brasil/EBC, 05/05/2020. Disponível em: https://agenciabrasil.ebc.com.br/saude/noticia/202005/covid-leva-classes-media-e-alta-de-sp-valorizar-o-sus-diz-pesquisa.
} 
recorrentes na mídia e pela mídia. Neste momento de pandemia, o SUS vivencia um certo "protagonismo", reforçando, assim, a necessidade de se estudar e de se falar sobre ele e sobre os processos comunicacionais em torno dele. Os sentidos sobre o sistema vão sendo construídos e reelaborados diariamente nas diferentes temporalidades a partir das múltiplas narrativas.

Nas páginas de jornal é possível localizar elementos discursivos que constituem instrumento essencial de politização ou de despolitização da sociedade. Em uma época em que muito se fala sobre a aceleração do tempo ${ }^{10}$, a necessidade de se deixar "pegadas" e rastros pode ser percebida como uma contribuição da imprensa nos processos de construção de memórias. Para nós, o jornal não será visto apenas como fonte, mas especialmente como importante ator social e político, pois consideramos os meios de comunicação, aqui em especial a imprensa, são os grandes mediadores entre o sujeito e o mundo.

Além disso, os jornais também devem ser vistos como espaços de disputas de poder. Os jornais são empresas e, como toda e qualquer empresa, disputas são travadas em seus interiores. Trabalham nos jornais profissionais diversos que possuem suas posições políticas e ideológicas. Esses profissionais também devem respeitar a linha editorial do jornal onde trabalham. Deste modo, deve-se considerar que a atividade jornalística não é uma atividade individual, mas, sim, uma atividade que exige trabalho de vários indivíduos que atuam coletivamente em uma empresa. Há valores, crenças, opiniões, que acabam sendo transpostos nas narrativas construídas pelos jornais, mesmo que muitas vezes discretamente.

Sendo assim, propomos algumas reflexões sobre os primeiros textos sobre o SUS, publicados pelo jornal $O$ Globo no ano de 1988. No que diz respeito ao referencial teóricometodológico utilizado no processo de investigação, optamos por seguir os pressupostos de autores que tomam a história e a memória como relevantes campos de produção do saber. Também buscamos nos inspirar em autores que propõem uma reflexão entre imprensa e história e/ou memória. Para pensar as questões de linguagem nas análises discursivas, nos ancoramos nas contribuições teóricas de Bakhtin (1992, 2016), com foco nos conceitos de polifonia e dialogismo, e na sua concepção dos discursos como lugares de lutas pelos sentidos.

A escolha do jornal $O$ Globo se deu por ser um jornal com uma longa trajetória (fundado em 1925) e com uma história que se entrecruza com a história republicana do Brasil. Além disso, a escolha se deu por ser um dos jornais de referência no país por décadas, tendo

${ }^{10}$ Ancoramos nossas visões sobre a problemática da aceleração do tempo histórico em reflexões propostas por Koselleck (2006) e Barbosa (2007). 
um importante papel no cenário político da nação, sendo dirigido a um público formador de opinião e, por ser um dos jornais de maior circulação no território nacional. Dados que conferem a ele um amplo poder de difusão de sentidos sobre o que publica. Sua força no mercado da imprensa permite que ele seja um influenciador de outros veículos de comunicação, pautando outras mídias, não apenas nas grandes capitais, mas inclusive nas regiões do interior do país.

Apresentamos uma breve exposição sobre a história do SUS e uma análise de textos jornalísticos sobre o sistema de saúde. No que se refere ao corpus e ao recorte temporal, realizamos pesquisa no acervo digital de $O G_{l o b o}{ }^{11}$, no ano de 1988 - ano em que a saúde passa a ser considerada direito assegurado em Constituição - e selecionamos alguns textos, numa amostra aleatória, a partir dos descritores: "SUS" e "saúde pública". Após localizarmos algumas das primeiras notícias sobre a criação do SUS, buscamos identificar os sentidos sobre o Sistema Único de Saúde que emergiram desses primeiros textos noticiados.

\section{Debates necessários}

A distinção entre memória e história pode ser observada com nitidez na produção intelectual de alguns autores, como Nora (1993), ao ressaltar que memória e história não podem ser vistas como sinônimos. Para ele, uma se opõe à outra. Nora (1993) considera que a memória é um fenômeno sempre atual, vivido no presente, enquanto a história seria uma representação do passado.

A memória é a vida, sempre carregada por grupos vivos e, nesse sentido, ela está sempre em permanente evolução, aberta à dialética da lembrança e do esquecimento, inconsciente de suas deformações sucessivas, vulnerável a todos os usos e manipulações, susceptível de longas latências e de repentinas revitalizações. A história é a reconstrução sempre problemática e incompleta do que não existe mais (NORA, 1993, p. 9).

Em seus estudos sobre memória coletiva, Halbwachs (2006) já enfatizava não somente a seletividade de toda memória, mas também a existência de um processo de "negociação" que vigora para conciliar memória coletiva com memórias individuais,

Para que nossa memória se beneficie da dos outros, não basta que eles nos tragam seus testemunhos: é preciso também que ela não tenha deixado de concordar com suas memórias e que haja suficientes pontos de contato entre ela e as outras para que a lembrança que os outros nos trazem possa ser reconstruída sobre uma base comum (HALBAWCHS, 2006, p. 12).

\footnotetext{
${ }^{11}$ Acervo disponível no endereço http://acervo.oglobo.globo.com/consulta-ao-acervo/?navegacaoPorData=1980.
} 
Pensar sobre produções de memórias é também pensar que não se trata apenas de uma produção individual, mas também há uma coletividade envolvida nesse processo. As construções coletivas estão repletas de temas que muitas vezes recebem aprovações e interesses para que sejam recontados e publicizados, assim como existem temas muitas vezes evitados e negligenciados pela história. A construção do relato histórico é sempre negociada e assumidamente parcial - os interesses em dar (ou não) visibilidade a assuntos do passado estão em constante seleção.

O trabalho de enquadramento da memória se alimenta do material fornecido pela história. Esse material pode sem dúvida ser interpretado e combinado a um sem-número de referências associadas; guiado pela preocupação não apenas de manter as fronteiras sociais, mas também de modificá-las, esse trabalho reinterpreta incessantemente o passado em função dos combates do presente e do futuro (POLLAK, 1989, p. 9-10).

Segundo Ricoeur (2007), os abusos da memória tornam-se abusos de esquecimento, pois, antes do abuso, há o uso, a saber, o caráter necessariamente seletivo da narrativa. Seria impossível realizar uma narração exaustiva e totalmente completa sobre o passado, já que seria humanamente impossível lembrar-se de tudo integralmente. Essas estratégias de esquecimento estão intrinsecamente ligadas às reais possibilidades de se narrar algo de modos distintos, suprimindo e deslocando ênfases, reconfigurando os protagonistas das ações, enfim, reconfigurando a narrativa. Ricoeur (2007, p.451), em sua obra A memória, a história e o esquecimento, ressalta que "lembrar-se é em grande parte, não esquecer".

A capacidade de tornar memorável, ou simplesmente deixar ao esquecimento questões abordadas pela mídia, parece-nos ser uma atenção necessária a ser dada ao papel, em especial, da imprensa. Considerando que a mídia é ator importante na sociedade e que ocupa um espaço privilegiado no mundo contemporâneo, debruçar-se sobre seus modos de narrar os fatos e fazer deles acontecimentos, e inclusive atentar para os fatos que são esquecidos e não ganham visibilidade na mídia, torna-se relevante para os estudos de comunicação e história.

Ao considerar que a história segue protocolos narrativos, que envolvem inclusive procedimentos em sua escrita, é necessário ponderar que a imprensa também tem suas maneiras de contar os fatos. Ao olhar para a história contada e produzida pelos jornais, é importante encarar os fatos jornalísticos como acontecimentos que se tornam memoráveis ou esquecidos na sociedade, pela maneira como são narrados.

Os suportes midiáticos acabam por dar sentidos aos eventos e colocam os fatos em 
formas discursivas, em molduras, e consequentemente transformam esses fatos em acontecimentos midiáticos. Tornam-se os jornais muito mais que arquivos memoráveis de uma sociedade, são eles, inclusive, atores muito atuantes na vida dos indivíduos e das nações. No simples fato de dar a ver o acontecimento, já se está interferindo nele.

Barbosa (2007) afirma que os meios de comunicação funcionam como um dos principais formuladores de tempo-mundo. "Temporalidade ou 'a forma como se inscrevem as atividades na duração"” (idem, p.63), logo, os meios de comunicação são marcadores temporais que podem contribuir para a história de um dado momento. Muitas vezes nos recordamos de algo a partir da maneira como a mídia nos trouxe os fatos ou até, a partir do modo como a mídia nos faz relembrar. Por vezes nos recordamos de algo que vimos na mídia e adotamos aquela narrativa como uma das principais referências na produção de nossas próprias memórias.

Ao escolher um jornal como objeto de estudo, análise e pesquisa, reforça-se o reconhecimento do papel da imprensa como instrumento de intervenção na vida das pessoas e das sociedades. Reconhece-se na imprensa elementos muito importantes na produção de memórias e identidades, conforme destaca Barbosa (2007, p. 81):

Ler um jornal, ver uma emissão de televisão, escutar um programa de rádio é estar intrinsecamente inserido no tempo, não só porque se desvenda o acontecimento e sua forma textual, mas porque esta narrativa está inserida na temporalidade do leitor e/ou espectador, pois é a partir da apropriação que o acontecimento se transforma em experiência vivida.

Dosse (2013) destaca que a mídia de massa participa plenamente da própria natureza dos acontecimentos que ela transmite, e que o acontecimento existe cada vez mais a partir da mídia: "Para ser, o acontecimento deve ser conhecido, e as mídias são de maneira crescente vetores dessa tomada de consciência” (DOSSE, 2013, p.260).

Considerando que se alguns segmentos da sociedade tomam os discursos midiáticos como apresentando a verdade dos fatos, outros setores muito desconfiam das narrativas da mídia - não por acaso, temos hoje, em 2020, muitas narrativas concorrendo, por exemplo, com os discursos jornalísticos no que diz respeito à atual pandemia de Covid-19. É preciso levar em conta que os discursos midiáticos são apenas uma das possíveis maneiras de se narrar um fato, ou seja, a versão contada na mídia e pela mídia não pode ser tomada como única e exclusiva.

Dito isso, reconhecemos o lugar privilegiado dos meios de comunicação, e os 
encaramos não como meros reprodutores de uma dada realidade, nem como espaços neutros e tampouco livres de interesses particulares. A mídia deve ser vista como espaço articulado e coerente de disputa de poder, cuja expressão dos interesses do capital, vinculados na maioria das vezes a grupos econômicos, não representam e nem defendem igualmente os interesses da sociedade.

\section{Quem é o SUS?}

É possível notar, nas últimas décadas, uma significativa diversidade de abordagens sobre a temática saúde nas páginas dos jornais. A nós, interessa um investimento específico: o SUS.

O SUS foi constituído fundamentalmente por três documentos que expressam os elementos básicos que estruturam e organizam o sistema de saúde brasileiro: 1) a Constituição Federal de 1988, que prevê que a saúde é um dos setores que estruturam a seguridade social, ao lado da previdência e da assistência social (BRASIL, 1988); 2) a Lei n. 8.080, de 19 de setembro de 1990, também conhecida como a Lei Orgânica da Saúde, que dispõe principalmente sobre a organização e regulação das ações e serviços de saúde em todo o território nacional (BRASIL, 1990a); 3) a Lei n. 8.142, de 28 de dezembro de 1990, que estabelece o formato da participação popular no SUS e dispõe sobre as transferências intergovernamentais de recursos financeiros na área da saúde (BRASIL, 1990b).

Segundo Paim et al (2011), a reforma do setor de saúde, no Brasil, caminhava na contramão das reformas que estavam sendo difundidas naquela época em relação ao resto do mundo, que questionavam a manutenção do estado de bem-estar social. A proposta brasileira começou a ganhar forma em meados da década de 1970 e estruturou-se durante a luta pela redemocratização do país. Os anos 1980 foram de instabilidade econômica, quando os movimentos sociais se retraíam, proliferava-se a ideologia neoliberal e os trabalhadores perdiam seu poder de compra. Simultaneamente à reforma sanitária, as empresas privadas de saúde estavam se reorganizando para atender às demandas de novos clientes, recebendo subsídios do governo e, consolidando-se um cenário onde havia cada vez mais investimentos nos setores privados.

Desde a sua criação, o SUS tem estado em meio a um campo de tensões. Gestores, políticos, usuários, imprensa apresentam uma multiplicidade de perspectivas sobre o que é e o que deveria ser o sistema, mobilizando, por vezes, debates inflamados. Por ser considerada 
uma grande conquista coletiva na década de 1980, o SUS - com pretensão de ser universal e integral - representou uma transformação na concepção do que se entendia por cidadania no país (MACHADO, 2014).

O SUS é reconhecido como um dos maiores e mais complexos sistemas de saúde pública mundial: possibilita acesso gratuito, integral e universal para toda população do país por meio da realização de atendimentos de baixa, média e alta complexidade e fornecimento de remédios e vacinas, conforme as recomendações da Organização Mundial da Saúde (OMS). Além disso, administra o maior banco de leite humano do mundo (GAMEIRO, 2019) e está entre os líderes das operações de transplantes de órgãos (DOAÇÃO..., 2021). De acordo com a Pesquisa Nacional de Saúde, divulgada em 04 de setembro de 2020 pelo Instituto Brasileiro de Geografia e Estatística $\left(\right.$ IBGE) ${ }^{12}$, sete em cada dez brasileiros (mais de 150 milhões de pessoas), dependem exclusivamente do SUS (PNS 2019..., 2020).

No decorrer das últimas três décadas (entre 1988 e 2018) nos deparamos com diversas narrativas sobre o SUS, a partir de diferentes atores sociais. Conforme mostra Bakhtin (1992, 2016), entre as múltiplas vozes existentes nos discursos, é importante reconhecer as práticas discursivas como lugares de disputas por hegemonia de sentidos. Ou seja, compreendemos essas múltiplas vozes existentes - o que Bakhtin denominou polifonia -, como instâncias de negociações e embates, discursos que não são excludentes, mas que se interligam e colaboram com a produção de sentidos sobre o SUS.

Para se discutir as múltiplas interfaces do SUS faz-se necessário levar em consideração que o sistema é repleto de camadas, que ele vem sendo construído ao longo do tempo, sendo descrito por diferentes atores e as narrativas sobre ele estão em circulação em múltiplas arenas discursivas. Essa circularidade discursiva acaba por possibilitar o aparecimento das diversas faces do SUS nas vozes de muitas fontes. Essas narrativas vão escoar e refletir, de alguma forma, na construção dos sentidos e nas memórias sobre o SUS.

\section{As primeiras notícias sobre o SUS no Globo}

A década de 1980 iniciou-se em clima de redemocratização no país, crise política, social e institucional do Estado Nacional. Esse clima que envolvia o país como um todo, na saúde em particular, também se refletia no jornalismo.

Ao nos debruçarmos sobre as narrativas do jornal $O$ Globo, encontramos em 18 de maio de 1988, na primeira página, informações sobre uma mudança no setor de saúde. Na

\footnotetext{
${ }^{12}$ Dados referentes ao ano de 2019.
} 
ocasião, o jornal noticiou a criação e inscrição na Constituição de um Sistema Único de Saúde que viria a ser um marco nas políticas brasileiras no setor. O texto jornalístico sobre o sistema de saúde foi apresentado de maneira bem indireta, em uma pequena nota na primeira página do jornal, sem foto, intitulada "Constituinte proíbe venda de sangue e derivados" (1988, p. 1):

A Constituinte aprovou ontem, por 313 votos contra 127 e 37 abstenções, emenda que proíbe a venda de sangue e seus derivados. As medidas de controle sobre a coleta, processamento e transfusão serão definidas por lei ordinária. Este dispositivo fora excluído do amplo acordo sobre o capítulo da Saúde (aprovado por 472 votos contra nove e seis abstenções), porque alguns setores do Centrão não concordavam com seu conteúdo.

A nova constituição cria o Sistema Único de Saúde, que dá ao Ministério da Saúde a coordenação nacional da assistência médica pública e extingue, na prática, o INAMPS. O sistema preserva a atuação da iniciativa privada, mas impede a participação de empresas estrangeiras.

Figura 1 - O Globo, 18 maio 1988, primeira página

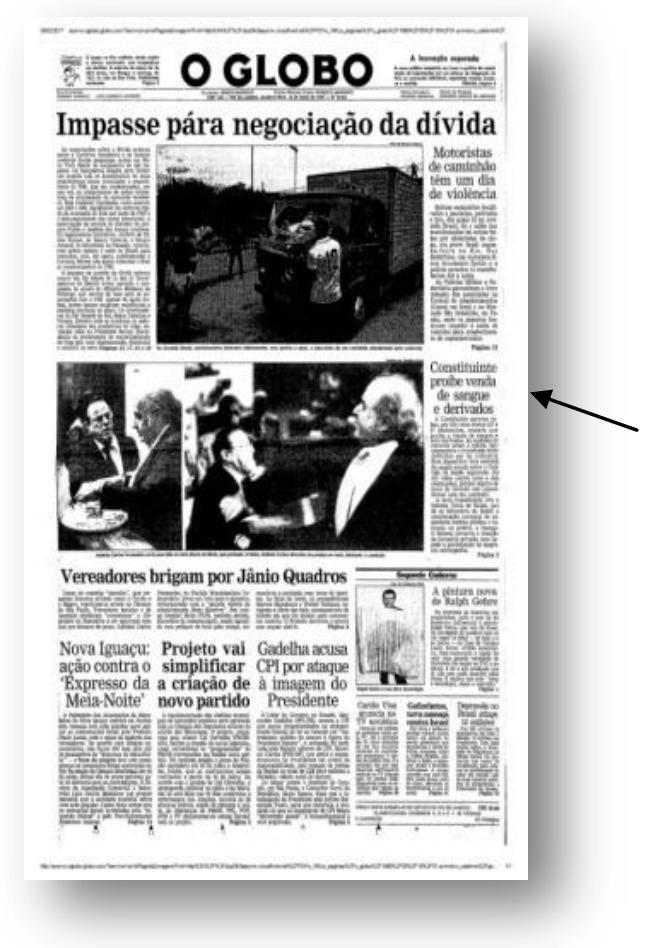

Fonte: Acervo Digital - Jornal $O$ Globo

Estar na primeira página de um jornal não é trivial. Trata-se de um espaço privilegiado e disputado entre os demais assuntos que ocupam a edição. Logo, pode-se inferir que a saúde pública foi considerada temática relevante. Também chamamos atenção para o fato de que o texto mais dava destaque ao comércio de sangue e hemoderivados, que a própria criação de um sistema único para a saúde. Pouco se fornece ao leitor de informação sobre o que a 
mudança no setor saúde impactaria na saúde pública do país.

Em 23 de setembro de 1988 o jornal publicou o texto da nova Carta em um caderno especial, com 26 páginas, contendo a íntegra do texto da Constituição de 1988. Nesse caderno, na página 16, o jornal reproduziu a Seção II - Da Saúde, seção onde as questões relativas ao tema estão dispostas no documento oficial. Apresentamos sequencialmente a primeira página daquele dia, a capa do caderno especial e a sua página 16, onde a Saúde está descrita conforme o texto da nova Carta (texto aprovado por 474 votos a favor, 15 contra e seis abstenções):

Figura 2 - A Constituição de 1988 - O Globo, 23/09/1988

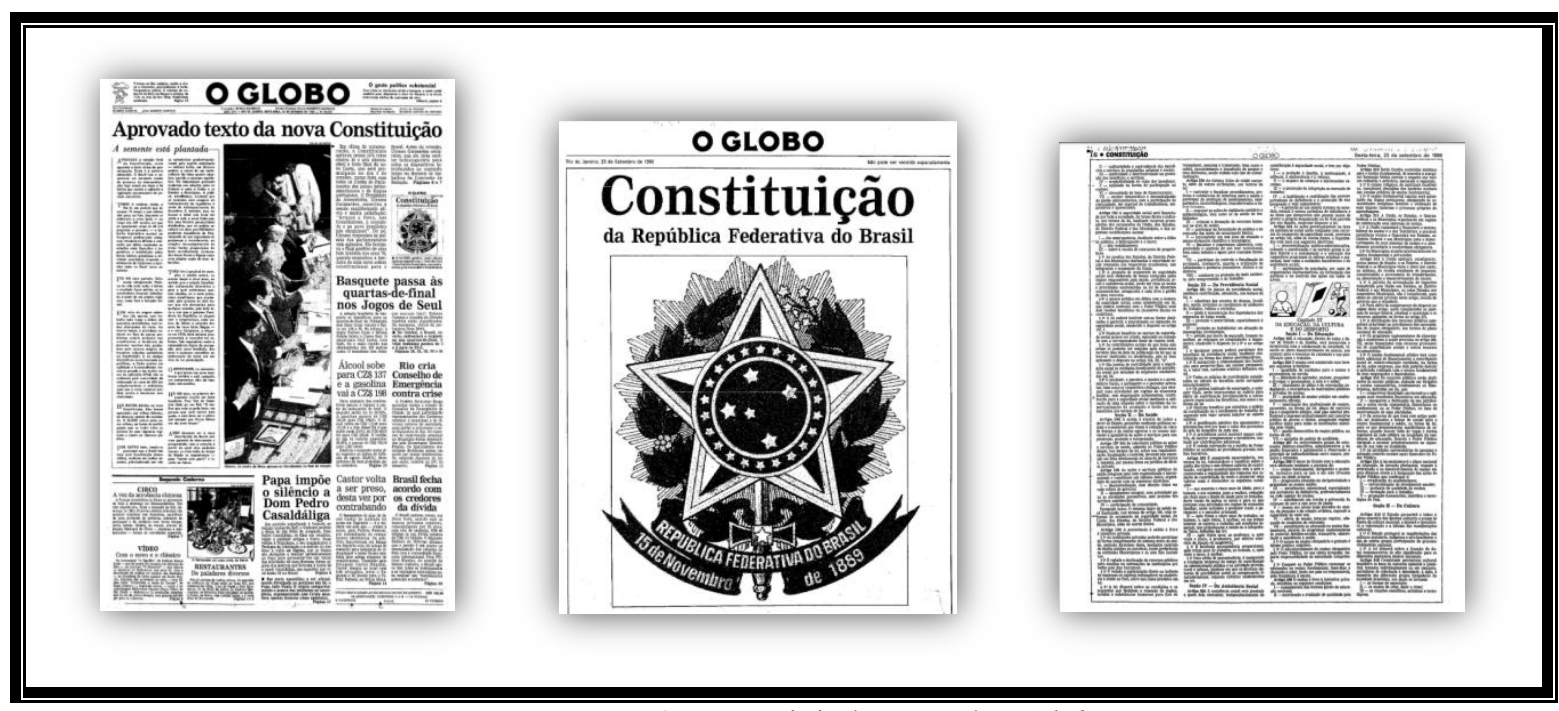

Fonte: Acervo Digital - Jornal O Globo

$O$ Globo ainda chamou atenção para o fato de que o então presidente da Assembleia Constituinte, Ulysses Guimarães, encerrou a sessão de votação (em 22/09) manifestando satisfação e alívio em seu discurso: "Graças a Deus, aos Constituintes, à sociedade, ao povo brasileiro, nós chegamos!” (APROVADO..., 1988, primeira página), mas não reproduziu o discurso na íntegra.

Os sentidos que emanam tanto do discurso de Ulisses Guimarães, quanto de um editorial publicado na mesma data, reverberam um desejo de deixar para trás um determinado tempo vivenciado pelo país na expectativa de se adentrar uma nova temporalidade. Havia uma expectativa de afastamento do passado e, concomitantemente, um desejo de aproximação com o futuro, ou seja, o desejo de trazer o futuro para perto do presente. No entanto, sabemos que apesar do desejo naquele momento, as camadas temporais não se rompem e não desaparecem 
simplesmente a partir da elaboração de um novo documento. O reflexo desse documento na área da Saúde, a partir da inserção da Saúde como direito, não seria visto imediatamente no dia a dia da população. O acesso aos serviços de saúde levaria algum tempo para ser reformulado. A promulgação da Constituição representava um avanço nas políticas sociais, mas reconhecer que o SUS está, ainda nos dias de hoje, em processo de consolidação, é importante.

Entre 15 de março de 1985 e 15 de março de 1990, a Presidência da República do Brasil foi exercida por José Sarney. Entre 23 de outubro de 1987 e 16 de janeiro de 1989, o ministro da Saúde era o médico Luiz Carlos Borges da Silveira. No Rio de Janeiro, sede do jornal O Globo, o governador do estado era Moreira Franco (1987-1991) e o prefeito da cidade do Rio era Saturnino Braga (entre 01/01/1986 e 15/09/1988). Saturnino teve uma gestão marcada por rupturas políticas e greves, tanto que no último ano do seu mandato decretou a falência do município e deixou o cargo em setembro de 1988. Assumiu a prefeitura o então vice-prefeito, Jó Antônio Rezende, em 15 de setembro de 1988, permanecendo no cargo até $1^{\circ}$. de janeiro de 1989 .

Nesse período, o país estava vivendo uma transição tanto no cenário político e social quanto na Saúde. Ainda vigorava o Instituto Nacional de Assistência Médica da Previdência Social (Inamps), passava-se por um momento de transição do Sistema Unificado e Descentralizado de Saúde (SUDS) e, futuramente, chegar-se-ia ao modelo do SUS. Lembramos que o Inamps foi criado em 1977, como uma autarquia federal vinculada ao Ministério da Previdência e Assistência Social. Foi criado no regime militar pelo desmembramento do Instituto Nacional de Previdência Social (INPS), que hoje é o Instituto Nacional de Seguridade Social (INSS). Já o SUDS foi um convênio entre o Inamps e os governos Estaduais. O SUDS possibilitou a formação de bases para a seção "Da Saúde" da Constituição Federal, que é considerada a primeira e grande conquista do Movimento da Reforma Sanitária, em 1988: a definição, na Constituição Federal (CF), do setor Saúde ${ }^{13}$ (SEMINÁRIO INTERNACIONAL TENDÊNCIAS E DESAFIOS DOS SISTEMAS DE SAÚDE NAS AMÉRICAS, 2002).

A recorrência de narrativas que mostram uma saúde pública em crise, especialmente por conta da falta de verbas e investimentos, levando os profissionais de saúde a recorrerem a paralisações e greves com frequência, já refletiam um cenário que não era dos mais favoráveis à saúde pública, antes mesmo da implantação do SUS.

\footnotetext{
${ }^{13}$ Mais informações a respeito desse momento da Saúde Pública brasileira podem ser consultadas em Seminário Internacional Tendências e Desafios dos Sistemas de Saúde nas Américas (2002).
} 
Em 02 de setembro de 1988, na editoria Grande Rio, p. 9 o jornal colocava em evidência o clima tenso existente entre o chefe do Escritório Regional do Inamps no Rio, Aparício Marinho, e o então secretário estadual da Saúde, José de Noronha, no texto intitulado "Inamps retoma o controle de hospitais" (INAMPS..., 1988, p. 9):

A Secretaria Estadual de Saúde não está mais gerindo a implantação do Sistema Unificado Descentralizado de Saúde (SUDS) nos órgãos do INAMPS. A decisão foi tomada pelo novo Chefe do Escritório Regional do INAMPS no Rio, Aparício Marinho, que em portaria baixada no último dia 29 , retomou o controle das 54 unidades do INAMPS no Estado, entre Hospitais e Postos de Atendimento Médico.

O Secretário Estadual de Saúde, José de Noronha, não quis comentar as declarações de Aparício Marinho, de que teria retomado o controle das unidades do INAMPS porque a Secretaria não estava conseguindo admistrar a implantação do SUDS. Como exemplo, o Chefe do Escritório Regionl do INAMPS citou a existência de medicamentos com data de validade vencidos, por falta de distrbuição, que estãona Central de Medicamanetos do INAMPS em Bonsucesso.

Ontem, ao tomar conhecimento da portaria, o Secretário Geral do Ministério da Previdência Social, Beline Guerra de Macedo, afirmou que a portaria será revogada, porque contraria o Decreto Presidencial 94.657, que criou o SUDS, e convêniosassinados entre o Estado e quaro Ministérios públicos para a implantação do sistema único de saúde no Rio de Janeiro [...] (INAMPS..., 1988, Grande Rio, p. 9). 
Figura 3 - "Inamps retoma o controle de hospitais" - O Globo, 02/09/1988, Grande Rio, p. 9

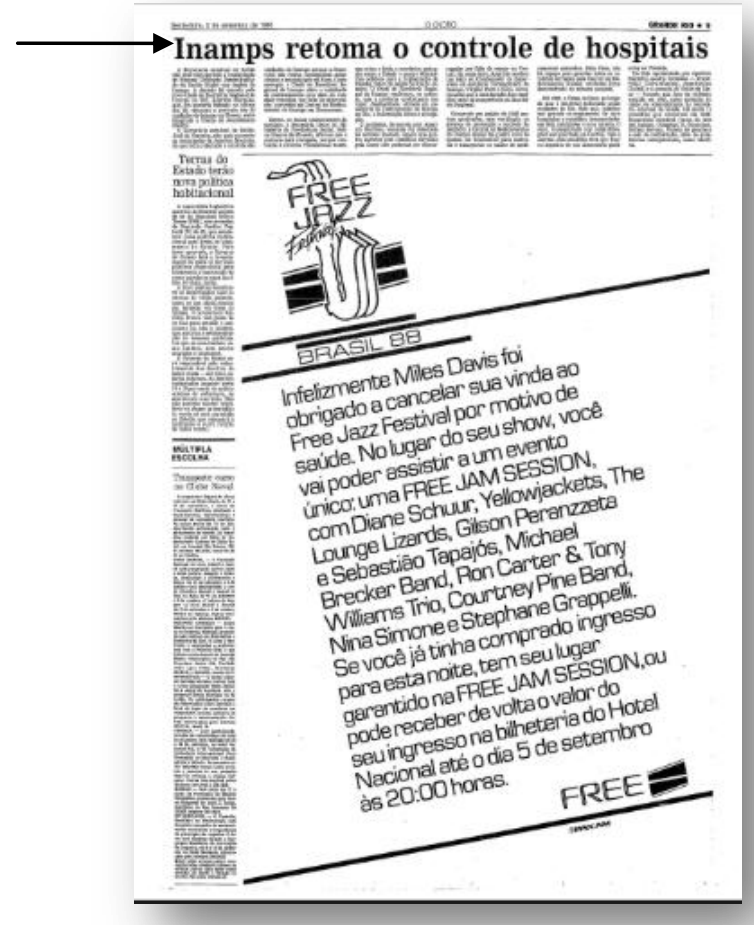

Fonte: Acervo Digital - Jornal O Globo

A disputa entre gestores da Saúde acerca das responsabilidades e obrigações do setor gerou debates em torno da futura implantação do SUS, mostrando que a criação do sistema único não se daria de modo pacífico. Tais narrativas, inclusive, ganharam espaço nas áreas destinadas a textos opinativos do jornal. Como a nota opinativa, de caráter editorialista, intitulada "Desmonte", publicada na edição de 04 de setembro de 1988, editoria O País, p. 7: 
Figura 4 - Nota opinativa "Desmonte" - O Globo, 04/09/1988; O País, p. 7
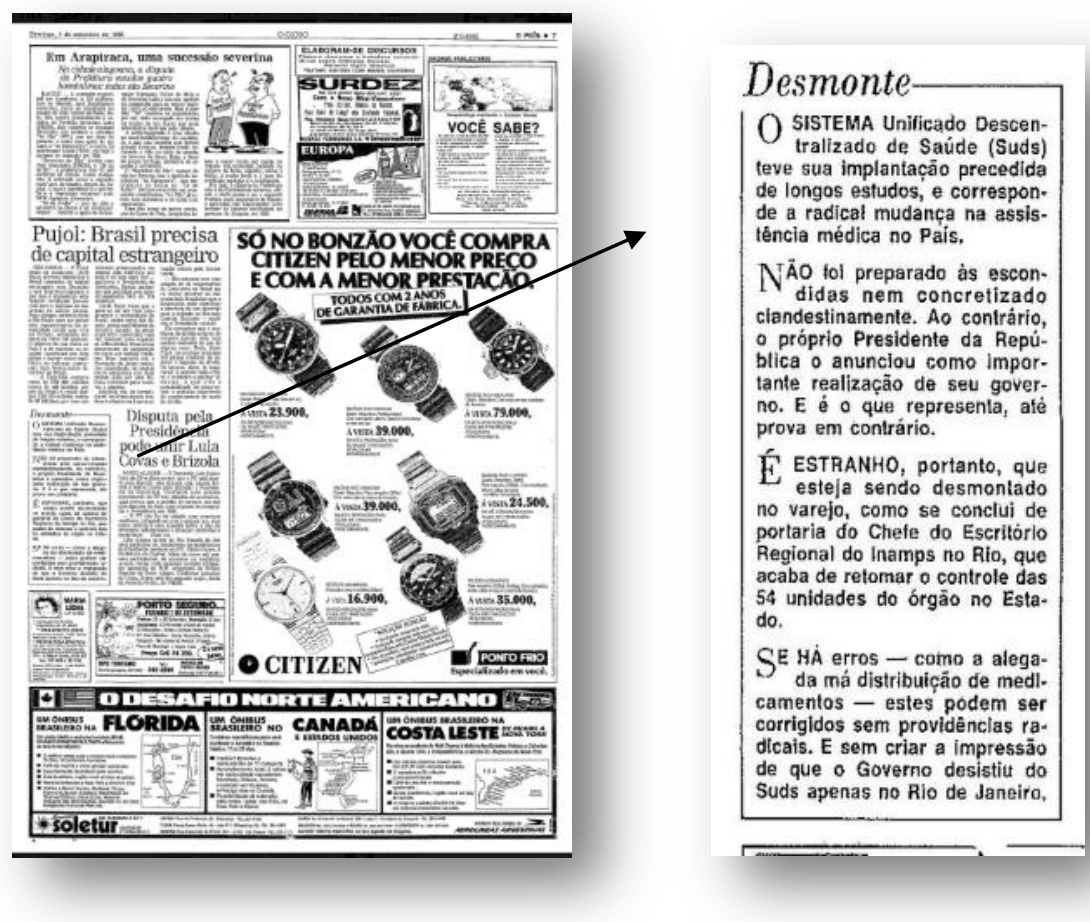

Fonte: Acervo Digital - Jornal $O$ Globo

Observa-se a defesa da implantação do SUDS em crítica aberta às decisões tomadas pelo chefe do Escritório do Inamps no Rio, que acabara de retomar o controle das unidades do órgão, antes sob responsabilidade do Governo do Estado do Rio. Nota-se a opinião do jornal a favor da implantação do SUDS.

Colabora com essa mesma visão, em comentário a esse texto do dia 4 de setembro, uma carta do leitor Walter Vilas Boas Meireles, publicada em 19 de setembro de 1988, na mesma editoria, na página 4, intitulada "Editorial". A postura que o jornal adotava nas narrativas, apresentando uma defesa do SUDS, contribuiu para uma sensação de apoio à implantação do sistema único e reforçou, em publicações de cartas como essa, a saúde como direito e interesse coletivo: 
Figura 5 - "Editorial”, carta de leitor, $O$ Globo, 04/09/1988, p.4

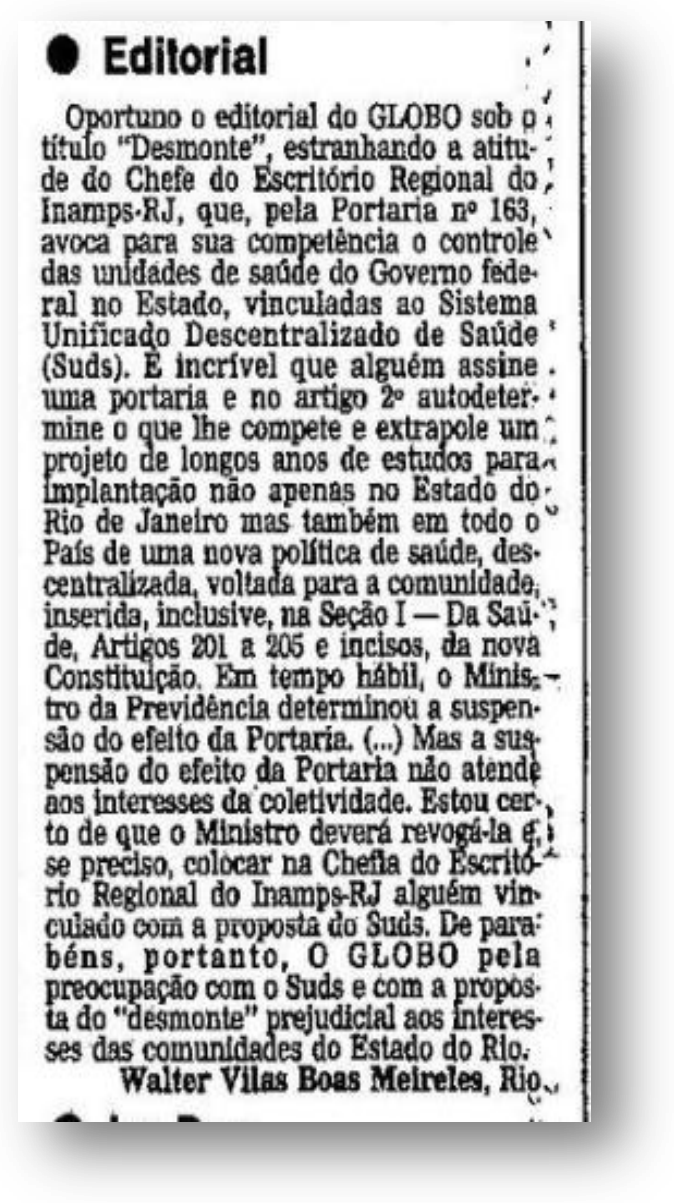

Fonte: Acervo Digital - Jornal $O$ Globo

Outra característica marcante dos textos de $O$ Globo, de 1988, diz respeito a questões financeiras vivenciadas pelo Rio de Janeiro, que também eram experimentadas pela Saúde. Alguns dos títulos apresentados nesse período que conformam essa perspectiva foram: “Assad: Saúde tem CZ\$ 7,4 bi a receber" (21/09); "Moreira ajudará Rio, 'doa a quem doer"” (22/09); "Paralisação na Previdência tem adesão de 80\%" (23/09); "Prefeito: Greve atrasará pagamento" (24/09); "Crise deixa Rio à beira do caos" (26/09); "SOS Rio - Cumpra-se a Constituição" (28/09); "Previdenciários decidem manter a paralisação" (29/09). Crise/Caos são termos que refletem os sentidos que encontramos nas narrativas sobre a saúde pública em O Globo, em 1988.

Dentre os textos observados, chamamos atenção para dois anúncios publicitários do Conselho Regional de Medicina do Estado do Rio de Janeiro (Cremerj), que datam, respectivamente, de 22 e 28 de setembro, ambos com conteúdo bastante similar. A seguir, o 
texto publicado em 28 de setembro de 1988, que colabora para a representação do momento como “delicado" na Saúde do Rio (editoria Grande Rio, p. 7):

Figura 6 - "SOS Rio: Cumpra-se a Constituição" - O Globo, 28/09/1988; Grande Rio, p.7
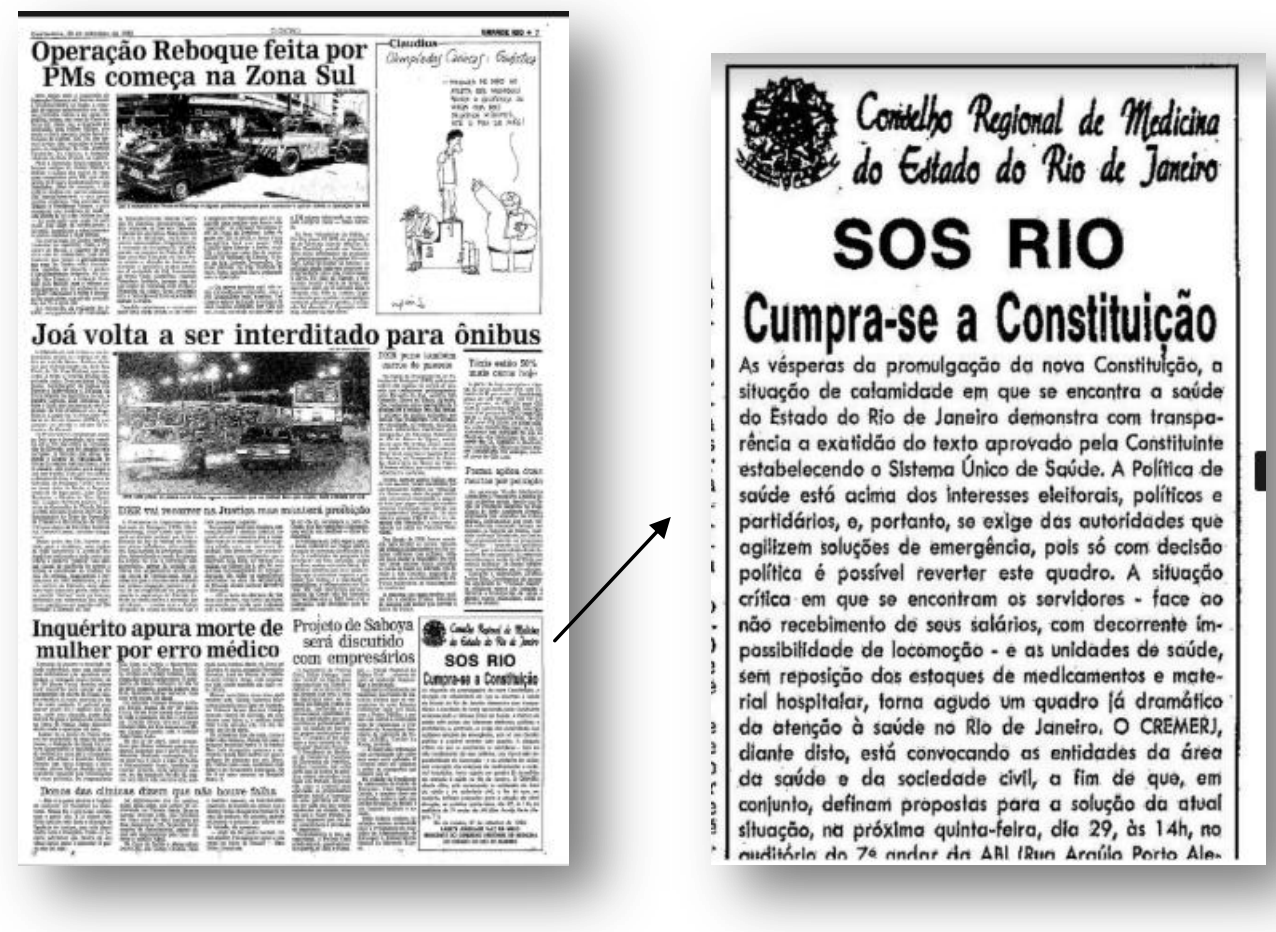

Fonte: Acervo Digital - Jornal $O$ Globo

O modo de se referir à saúde pública, como "SOS Rio", "situação de calamidade", "soluções de emergência", "situação crítica", "não recebimento de seus salários”, "unidade de saúde sem reposição de estoques de medicamentos e material hospitalar", "torna agudo um quadro já dramático", dão a ver o contexto sociocultural em que a saúde no Rio se encontrava desde antes da implantação efetiva do SUS.

A recorrência de textos jornalísticos, sobre uma saúde pública em crise, em 1988, e os conteúdos por eles apresentados, mostra que a saúde pública do país, mesmo antes da implantação do SUS, estava carregada de sentidos que remetem à crise, à falta de dinheiro, à frágil situação financeira em que os profissionais de saúde se encontravam. Consideramos que os contextos, tanto de produção das narrativas, quanto daquilo que elas retratam, contribuem para a produção de sentidos sobre a saúde pública no Brasil e revelam que a Saúde está diretamente atrelada a condições políticas e econômicas. 
Mesmo a saúde tendo passado a ser reconhecida como direito constitucional em 1988, houve ainda um período de transição entre o modelo de saúde pública existente até então e a institucionalização do SUS. Lembramos que a extinção do Inamps só ocorreu alguns anos à frente, com a Lei n. 8.689, de 27 de julho de 1993 (BRASIL, 1993), de modo que as discussões em torno dos hospitais do Inamps e do atendimento do SUS nas redes municipais e estaduais enfrentariam, ainda, algum tempo de entraves.

A disputa política a respeito do controle da saúde pública no Rio, e sobre a gestão dos hospitais do Inamps, ganhava bastante espaço no debate público, nas páginas do jornal. Além disso, narrativas que traziam à tona uma crise política dentro do Estado do Rio aproximavam as questões da saúde à dimensão do "caos", como o jornal nomeava. Essa crise ocorria, sobretudo, no campo econômico.

\section{Considerações finais}

Este texto é fruto de estudo que apresentei em minha tese de doutorado ${ }^{14}$ cuja proposta foi estudar os sentidos do SUS ao longo dos seus 30 primeiros anos de existência, nas páginas do jornal $O$ Globo.

A partir do reconhecimento de que tanto o jornalismo quanto a saúde pública são assuntos relevantes para a sociedade como um todo, ressalto, como premissa fundamental, olharmos com cuidado para a contribuição que os jornais impressos têm na construção da memória histórica e social acerca da institucionalização das políticas públicas de saúde.

Apesar de sua centralidade, a imprensa nos fornece apenas uma parte da memória sobre a constituição do SUS. Também reconheço que o material escolhido para o exercício de análise neste texto não revela toda a memória criada pela imprensa, ao longo do tempo, sobre o Sistema Único de Saúde. Não fornece uma radiografia unânime e universal da memória construída sobre o SUS no jornal $O$ Globo, mas traz importantes elementos para outras reflexões possíveis, entre elas, a proximidade entre algumas coberturas realizadas em 1988 e nos tempos atuais.

Perceber o quanto as políticas de saúde sempre estiveram atreladas a questões e interesses políticos e financeiros ao longo da história do país é um passo necessário para se entender o processo de constituição do SUS. Estar atento aos atores sociais envolvidos e

\footnotetext{
${ }^{14} \mathrm{Na}$ tese $O$ SUS midiático: historicidades e sentidos sobre saúde pública no jornal O Globo (1988-2018), apresentada em 2020, defendo a ideia da existência de um SUS midiático que contribui para a construção de memórias sobre o Sistema Único de Saúde. Considero que o jornalismo é ator fundamental na produção de sentidos sobre o SUS e um dos responsáveis pela produção das memórias discursivas em torno do sistema público de saúde.
} 
compreender os jogos de interesses em disputas aponta brechas para diversas interpretações e compreensões desse processo histórico.

Em relação ao questionamento no início deste texto, sobre a quem compete contar/construir a história e a memória, arrisco dizer que muitos são os atores e fontes com tais habilidades, mas certamente um não exclui o outro. A multiplicidade de vozes existentes é necessária para contar e recontar fatos já vividos. A mídia certamente é uma das vozes possíveis, ela mesma, por vezes, polifônica.

Historicamente, as políticas de saúde no Brasil sempre estimularam o setor privado de saúde e, consequentemente, incentivaram a privatização da atenção à saúde. As disputas de sentidos entre público e privado estão desde sempre presentes nas narrativas em torno do SUS. O apoio aos serviços privados de saúde se reflete, em certa medida, não apenas nas políticas de saúde, mas também nas narrativas jornalísticas, inclusive se considerarmos que as operadoras de planos de saúde são grandes anunciantes na imprensa.

É a linguagem que dá vida aos fatos e acontecimentos. O SUS é composto por várias camadas, entre elas, aquela constituída pelas narrativas sobre o próprio sistema. Quando se dá visibilidade a algo, consequentemente deixa-se de dar visibilidade a outras situações. Aplicase isso às narrativas jornalísticas. Ao escolher narrar uma situação, acaba-se deixando outras de lado. Assim como nas ações de memória, assim também funciona na mídia. A seletividade dos fatos consequentemente dá luz a determinadas situações e simplesmente apagam tantas outras. Os acontecimentos são em si inapreensíveis, por isso as narrativas nunca darão conta da totalidade dos fatos. Daí, inclusive, a importância de se cruzar dados e relatos de fontes e atores distintos sobre um fato ou acontecimento. Assumindo a importância e legitimidade dos jornais como fontes históricas, ressaltando que só se pode afirmar que existe memória porque também existe esquecimento. Com isso, podemos concluir que o SUS que temos hoje é também resultado das múltiplas narrativas sobre ele que foram produzidas ao longo do tempo. 
Referências

APROVADO texto da nova Constituição. O Globo, Rio de Janeiro, p. 1, 23 set. 1988.

Disponível em: https://acervo.oglobo.globo.com/. Acesso em: 14 out. 2020.

BAKHTIN, Mikhail. Marxismo e filosofia da linguagem. São Paulo: Hucitec, 1992.

BAKHTIN, Mikhail. Os gêneros do discurso. São Paulo: Editora 34, 2016.

BARBOSA, Marialva. Percursos do olhar: Comunicação, narrativa e memória. Rio de Janeiro, EdUFF, 2007.

BARBOSA, Marialva. Meios de comunicação: lugar de memória ou na história?

Contracampo, v. 35, p. 7-26, 2016. Disponível em:

https://periodicos.uff.br/contracampo/article/view/17558/pdf . Acesso em: 15 jun. 2017.

BARBOSA, Marialva; RIBEIRO, Ana. Paula Goulart (org.). Comunicação e História: políticas teóricas. Florianópolis: Insular, 2011.

BRASIL. Constituição da República Federativa do Brasil,1988. Cap.II - Da Seguridade Social - Seção II: Da Saúde (art. 196 a 200). Disponível em:

http://www.senado.leg.br/atividade/const/con1988/CON1988_05.10.1988/art_200_.asp.

Acesso em: 15 jun. 2017.

BRASIL. Lei $\mathbf{n}^{\mathbf{0}}$ 8.689, DE 27 de julho de 1993. Dispõe sobre a extinção do Instituto Nacional de Assistência Médica da Previdência Social (Inamps) e dá outras providências. Disponível em: http://www.planalto.gov.br/ccivil_03/leis/18689.htm. Acesso em: 17 nov. 2020.

BRASIL. Presidência da República. Lei n. 8.080, de 19 de setembro de 1990. Dispõe sobre as condições para a promoção, proteção e recuperação da saúde, a organização e o funcionamento dos serviços correspondentes e dá outras providências. Diário Oficial da União, Brasília, 20 set. 1990a.

BRASIL. Presidência da República. Lei n. 8.142, de 28 de dezembro de 1990. Dispõe sobre a participação da comunidade na gestão do Sistema Único de Saúde (SUS) e sobre as transferências intergovernamentais de recursos financeiros na área da saúde e dá outras providências. Diário Oficial da União, Brasília, 31 dez. 1990 b.

CHARTIER, Roger. O passado no presente: ficção, história e memória. In: ROCHA, João Cezar C. (org.). A força das representações: história e ficção. Chapecó: Argos, 2013, p.95124.

CONSTITUINTE proíbe venda de sangue e derivados. O Globo, Rio de Janeiro, p. 1, 18 maio 1988. Disponível em: https://acervo.oglobo.globo.com/. Acesso em: 14 out. 2020.

DESMONTE. O Globo, Rio de Janeiro, 04 set. 1988. Editoria O País, p. 7. Disponível em: Disponível em: https://acervo.oglobo.globo.com/. Acesso em: 14 out. 2020. 
DOAÇÃO de órgãos: transplantes, lista de espera e como ser doador. Ministério da Sáude, Brasília, 2021. Disponível em: https://antigo.saude.gov.br/saude-de-a-z/doacao-de-orgaos. Acesso em: 14 nov. 2020.

DOSSE, François. O renascimento do acontecimento. São Paulo: Unesp, 2013.

EDITORIAL. O Globo, Rio de Janeiro, 04 set. 1988. Editoria O País, p.4. Disponível em: Disponível em: https://acervo.oglobo.globo.com/. Acesso em: 14 de out. de 2020.

FRANÇA, Vera Regina Veiga. Representações, mediações e práticas comunicativas. In: PEREIRA, Miguel; GOMES, Renato Cordeiro; FIGUEIREDO, Vera Lúcia Follain de. Comunicação, representação e práticas sociais. Rio de Janeiro: PUC Rio; Aparecida: Idéias \& Letras, 2004, p.13-26.

FRANÇA, Vera Regina Veiga. O acontecimento e a mídia. Galáxia, São Paulo, n. 24, p. 1021, dez. 2012.

GAMEIRO, Nathália. Brasil é referência mundial em Bancos de Leite Humano. Fiocruz Brasília, Brasília, 29 ago. 2019. Disponível em: https://www.fiocruzbrasilia.fiocruz.br/brasile-referencia-mundial-em-bancos-de-leite-humano/. Acesso em: 14 nov. 2020.

HALBWACHS, Maurice. A memória coletiva. São Paulo: Centauro, 2006.

HUYSSEN, Andreas. Passados presentes: mídia, política e amnésia. In: Seduzidos pela memória: arquitetura, monumentos, mídia. Rio de Janeiro: Aeroplano, 2000, p.9-40.

INAMPS retoma o controle de hospitais. O Globo, Rio de Janeiro, 2 set. 1988. Editoria Grande Rio, p. 9. Disponível em: https://acervo.oglobo.globo.com/. Acesso em: 14 out. 2020.

KOSELLECK, Reinhart. Futuro passado: contribuição à semântica dos tempos históricos. Rio de Janeiro: Contraponto: Ed. PUC-Rio, 2006.

LANGBECKER, Andrea; CASTELLANOS, Marcelo Eduardo Pfeiffer; CATALANMATAMOROS, Daniel. Quando os sistemas públicos de saúde são notícia: uma análise comparativa da cobertura jornalista no Brasil e na Espanha. Ciênc. Saúde Coletiva, Rio de Janeiro, v. 25, n. 11, p. 4281-4292, nov. 2020. Disponível em: http://www.scielo.br/scielo.php?script=sci_arttext\&pid=S1413$81232020001104281 \& \operatorname{lng}=$ en\&nrm=iso. Acesso em: 15 nov. 2020.

MACHADO, Izamara Bastos. Percepções sobre o SUS: o que a mídia mostra e o revelado em pesquisa. In: LERNER, Kátia; SACRAMENTO, Igor (org.). Saúde e Jornalismo: interfaces contemporâneas. Rio de Janeiro: Editora FIOCRUZ, 2014, p. 235-250.

MACHADO, Izamara Bastos. O SUS midiático: historicidades e sentidos sobre saúde pública no jornal O Globo (1988-2018). 2020. Tese. (Doutorado em Comunicação e Cultura) - Escola de Comunicação, Universidade Federal do Rio de Janeiro, Rio de Janeiro, 2020.

MEIRELES, Walter Vilas Boas Meireles. Editorial. O Globo, Rio de Janeiro, 19 set. 1988. Editoria O País, p. 4. Disponível em: https://acervo.oglobo.globo.com/. Acesso em: 14 out. 
2020.

NORA, Pierre. Entre memória e História: a problemática dos lugares. Projeto História, São Paulo, n. 10, p. 7-28, dez. 1993. Disponível em:

https://revistas.pucsp.br/index.php/revph/article/view/12101/8763. Acesso em: 10 nov. 2017.

PAIM, Jairnilson; TRAVASSOS, Claudia; ALMEIDA, Celia; BAHIA, Ligia; MACINKO, Jamaes. O sistema de saúde brasileiro: história, avanços e desafios. Lancet, v. 377, n. 9779, p. 1778-1797, 9 maio 2011. Disponível em: https://actbr.org.br/uploads/arquivo/925_brazil1.pdf. Acesso em 10 nov. 2020.

PNS 2019: sete em cada dez pessoas que procuram o mesmo serviço de saúde vão à rede pública. Agência IBGE notícias, Brasília, 04 set. 2020. Disponível em: https://agenciadenoticias.ibge.gov.br/agencia-sala-de-imprensa/2013-agencia-denoticias/releases/28793-pns-2019-sete-em-cada-dez-pessoas-que-procuram-o-mesmo-servicode-saude-vao-a-rede-publica. Acesso em: 14 out.2020.

POLLAK, Michael. Memória, esquecimento, silêncio. Estudos Históricos, Rio de Janeiro, v. 2, n.3, 1989, p.3-15.

POLLAK, Michael. Memória e Identidade Social. Estudos Históricos, Rio de Janeiro, vol. 5, n. 10,1992 , p. 200-212.

RIBEIRO, Ana Paula Goulart. A história do seu tempo: a imprensa e a produção do sentido histórico. 1995. Dissertação (Mestrado em Comunicação e Cultura) - Escola de Comunicação, Universidade Federal do Rio de Janeiro, Rio de Janeiro, 1995.

RIBEIRO, Ana Paula Goulart. Entre memória e esquecimento: a mídia e os diferentes usos do passado. In: RÊGO, Ana Regina; QUEIROZ, Teresinha; MIRANDA, Marcela (org.).

Narrativas do jornalismo e narrativas da história. Porto: Media XXI, 2014.

RICOEUR, Paul. O esquecimento. In: A memória, a história, o esquecimento. Campinas, SP: Editora da Unicamp, 2007, p. 423-462.

SEMINÁRIO INTERNACIONAL TENDÊNCIAS E DESAFIOS DOS SISTEMAS DE SAÚDE NAS AMÉRICAS. O Sistema Público de Saúde Brasileiro. Ministério da Saúde, São Paulo, Brasil, 11 a 14 de agosto de 2002. Disponível em: https://bvsms.saude.gov.br/bvs/publicacoes/sistema_saude.pdf. Acesso em: 14 out. 2020.

SOS Rio - Cumpra-se a Constituição. O Globo, Rio de Janeiro, 28 set. 1988. Editoria Grande Rio, p. 7. Disponível em: https://acervo.oglobo.globo.com/. Acesso em: 14 out. 2020.

Submetido em 30.09.2020

Aprovado em 07.11.2020 